\title{
Using Numerical Simulation and Artificial Neural Networks to Investigate the Influence of Flood Control Infrastructures
}

\author{
Ying-Yu Ku ${ }^{1}$ and Vincenzo Naddeo | ${ }^{1}$ \\ ${ }^{1}$ Affiliation not available
}

January 20, 2022

\begin{abstract}
:
In recent years, global warming has increased the frequency and severity of extreme storm events, super typhoons, and short-duration and high-intensity rainfall events. Along with the growing awareness of sustainable development, Low Impact Development (LID) techniques are advocated to mitigate the impact on the environment to reduce surface runoff and to reduce the heat island effect.

The main purpose of this study is to investigate the effect of different stormwater facilities for different storm sizes on urban areas. The study areas are the flood-prone areas of Tu-Cheng downstream. In this study, four different cases are designed for comparison with the LID approach, including non-stormwater facilities, drainage channels with lower (silty loam) or higher (sandy clay load) infiltration rates, and drainage channels with lower infiltration rates and retention storage ponds. The FLO-2D model is applied for two-dimension flood distribution on the study areas of different designed cases, and Self-Organizing Map (SOM) is used to categorize the simulation data into a meaningful and visible inundation topology for displaying the regional flood inundation extents and severity of these four cases.
\end{abstract}

\section{Keywords:}

Artificial Neural Networks, Self-Organizing Map (SOM), Numerical Simulation, FLO-2D, Flood mitigation facilities, Flood Inundation

\section{Overview:}

\section{Introduction}

About three to four typhoons hit Taiwan every year and the average annual rainfall is about 2,500 $\mathrm{mm}$. The rainfall is concentrated in May to November each year which brings abundant water to Taiwan. However, due to the high development of Taiwan's cities, the buildings are so dense that the impervious areas are almost covered. In the whole city, the land use has exceeded the load of the natural environment, the soil permeability is poor and the surface runoff has greatly increased, resulting in insufficient drainage facilities to discharge and cause flooding. Therefore, how to increase the urban water retention rate and reduce the impact of urban development on the environment becomes one of the major issues for water resources management.

\section{Purpose}

Taking the flooding in the Tu-Cheng area as the research object, the numerical software FLO-2D is used to 
establish the flooding situation generated by different combinations of Low Impact Development facilities and to explore the best flood reduction effect by LID facilities. In addition, Self-Organizing Map (SOM) is used to carry out the cluster analysis to explore the correlation characteristics of flood mitigation factors with flooding conditions. Finally, it is expected that the results of this analysis can effectively solve the problem of urban flooding.

\section{Study area}

Tu-Cheng district is a municipal district of New Taipei City, with a population of about 240,000 and an area of about 30 square kilometers. It is located in the southwest corner of the Taipei Basin, and the northeast corner is adjacent to Banqiao District. The Southeast is backed by mountains and faces the water. Its location map is listed as vulnerable to flooding. Due to the highly developed and densely populated areas, the loss of flooding can be quite heavy.

\section{Methodology}

\subsection{FLO-2D}

This model is a two-dimensional flood disaster simulation model developed by an American company. It uses a one-dimensional variable flow model and a two-dimensional overland flow model to simulate one-dimensional flow, street flow, and two-dimensional overland flow. When the overflow occurs, the interaction mechanism between the channel outside the embankment and the surface of the embankment can be calculated which can effectively simulate the flooding situation. The model channel calculation method is to use the continuous equation and the dynamic wave model to simulate the finite difference method, simulate the speed and depth of fluid flow and estimate the reasonable submerged area as a flood disaster prediction tool.

\subsection{Self-Organizing Map (SOM)}

The SOM, introduced by Kohonen (1982), is a useful clustering method that can classify a large set of high-dimensional data to form a meaningful topological map derived from the low-dimensional (usually twodimensional) output layer of the network. The topological map can be used to visibly conduct an assessment of the behavior of input variables and the multi-relations among variables through the constructed clusters. The SOM has advantages of information extraction and visualization and has been widely used in water resources problems.

\subsection{Low Impact Development (LID)}

The main purpose of LID is to apply flood retention, infiltration and evaporation that are common in current drainage design and planning, and to increase urban park green space, so as to delay the flood peak when floods come and reduce flood volume to maintain the hydrological state before land development as much as possible.

\section{Expected results}

This study is to collect the elevation date distributed in the Tu-Cheng urban area, the rainfall data from the Tu-Chung rainfall stations, and the satellite imagery to build houses, roads and channels. Besides, the purpose is to explore the effect of different flood mitigation facilities on urban flooding. Taking the flooding situation in the downstream easily flooded area of Tu-Chung district as the research object, the numerical software FLO-2D simulated the flooding situation of different flood mitigation facilities. The flood reduction effect of the combination of LID facilities, and use the SOM to conduct cluster analysis to observe the interactive relationship between the trend of flooding and the factors of flood mitigation facilities, and provide the lowest environmental damage and can improve its maximum reduction. 


\section{Reference}

(1)Batesa, P.D., Horrittb, M.S. and Fewtrella, T.J., 2010. A simple inertial formulation of the shallow water equations for efficient two-dimensional flood inundation modelling. Journal of Hydrology 387(1-2):33-45.

(2)Chang, L. C., Shen, H. Y., Wang, Y. F., Huang, J. Y., \& Lin, Y. T.(2010).Clustering-based hybrid inundation model for forecasting flood inundation depths. Journal of hydrology, 385(1), 257-268.

(3)Chang, F. J., Chang, L. C., Kao, H. S., \& Wu, G. R. (2010). Assessing the effort of meteorological variables for evaporation estimation by self-organizing map neural network. Journal of Hydrology, 384(1), $118-129$.

(4)Chen, A. S., Evans, B., Djordjević, S., \& Savić, D. A. (2012).Multi-layered coarse grid modelling in 2D urban flood simulations.Journal of hydrology, 470, 1-11.

(5)Davis, A. P. (2005). Green engineering principles promote low-impact development. Environmental science \& technology, 39(16), 338A-344A.

(6)Dietz, M. E. (2007). Low impact development practices: A review of current research and recommendations for future directions. Water, air, and soil pollution, 186(1-4), 351-363. 